\title{
Stress Behavior Improvement Analysis of Automobile Flywheel Experimentally and Numerically
}

\author{
Çağlar İmer ${ }^{1}$, Samet Kartal ${ }^{1}$, Mehmet Onur Genç ${ }^{1}$
}

${ }^{1}$ Valeo Automotive Systems, Bursa, Turkey

\begin{abstract}
Clutch components rotating at high speed remain under the influence of high centrifugal forces. Therefore at the high rotational speeds flywheel is subjected to extreme forces that may cause severe cracks and breakages. Burst test validates the mechanical robustness of the flywheel under various rotational speeds. In this study comparative analysis have been performed experimentally and numerically in order to confirm correlation of the results. Centrifugal endurance test called burst have been performed in addition to finite element analysis which has been used for calculating stress values of flywheel. Additionally design of experiment method has been used for obtaining the response surface that approximates the stress behavior of automobile flywheel. This provides strong correlation between FEA results and data fittings calculation that gives extra contribution to reduce the design process. According to this correlation maximum $2.32 \%$ deviation was observed. This study gives ideas for the stress improvement of flywheel by making experimental and numerical comparison. In addition, $2.5 \%$ correlation ratio was found between experimental and numerical results. Experimental and numerical correlations results taken from this study can be used on the estimation of design robustness instead of prototypes production which causes time and money consumption during flywheel design and production process.
\end{abstract}

Keywords: Centrifugal forces; Flywheel; Experimental method; Stress replacement; Response surface

\section{* Corresponding author \\ Çağlar İmer \\ caglar.imer@valeo.com}

Adress: Valeo Automotive

Systems,Bursa, Turkey

Manuscript Received 19.10.2017

Revised 12.12.2017

Accepted 15.02.2018

Doi: 10.30939/ijastech..345185

\section{Introduction}

Flywheel is one of the main components of the transmission system in terms of continuous torque durability in automobiles. The flywheel is directly exposed to high centrifugal forces. Due to the importance of the flywheel, the durability of the flywheel must be investigated under high centrifugal force.

In this study, flywheel verification process is described with numerically and experimentally results. As a result of the study, developed finite element model is matched well with the experimental results.

Karpat et al. (2017) investigated the tractor clutch cover burst endurance against to centrifugal forces during dynamic driving conditions. In this study they made FEA analysis to clutch cover in order to simulate burst conditions [1]. Karpat et al. (2014) investigated tractor finger mechanism by using FEA in ANSYS. PTO finger working conditions are modeled in this study. The stress distribution were obtained for different thickness [2]. Dogan et al. (2015) designed tractor clutch finger by using topology and shape optimization [3]. Dogan et al. (2016) created new design procedure for tractor clutch finger mechanism by using FEA method [4].

Charles (2012) investigated in the study mechanical properties of flywheel in terms of energy storage and mass regulator component. Flywheel is the energy storage component that keeps the dissipated energy with the high mechanical characteristic. This study includes the experimental and mathematical approach to powertrain system analysis. In order to make further analysis flywheel constraints were defined coming from rotational forces and heat transfer [5]. Abdullah et al. (2013) studied the frictional clutch components relations in terms of stress and deformations. In the study contact points during driving condition were investigated by using finite element method. Conclusion was found that clutch system which is subjected to dynamic forces during high rotational speeds should be optimized to reduce stress which causes cracks and breakages [6]. Maninder et al. 


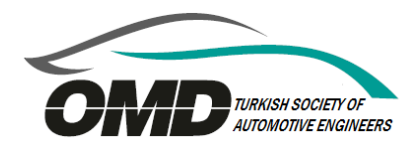

(2015) studied in this paper the optimization of flywheel mass by using computer aided analysis. Flywheel optimized geometry was investigated by using specific energy calculation in terms of components life limit. Authors emphasized in their study that flywheel geometry, mass and stress distribution have strong relation with each constraints on design parameters [7]. Abdullah and Schlattmann (2013) made further analysis on clutch systems centrifugal forces during engagement phase by using FEA based on the key components of clutch system such as flywheel, pressure plate and diaphragm spring [8]. Abdullah and Schlattmann (2012) investigated in their study the engagement phase between clutch disc and flywheel. In this study the slipping between two contact surfaces were modeled in FEA and design proposals were shared with clutch system designers [9]. Hongliang et al. (2017) studied flywheel energy storage ability for hybrid powertrain systems. In this study experimental and numerical results were compared and correlation was done between two results [10]. Ozansoy et al. (2015) investigated the optimal design of clutch systems. In this study they make simulation of clutch engagement phase and made proposals for the clutch designers [11].

In this study experimental and numerical studies were conducted to automotive flywheel which is operating under high centrifugal forces. At first stage, FEA analysis was performed to investigate burst improvement by response surface methodology, and then experimental comparative tests were done to correlate FEA results. This paper approaches to stress improvement both numerically and experimentally by using optimization methodology.

\section{Material and Method}

\subsection{FEA Study}

In this study, the components in vehicles subjected to high rotational speeds are investigated in terms of the stress behavior on design variations with FEA analysis at Ansys software and experimental bench tests for real conditions [12]. In order to validate the design of flywheel under high speed condition, burst test is performed with adapted bench test which simulates the real conditions as in vehicle. Duration of preparing test parts takes longer times due to prototyping processes such as casting mold production and schedule availability in serial production lines. Also implementation of flywheel prototypes with different designs is cost due to produce a casting mold for each flywheel design. Therefore finite element and experimental correlation solutions are helpful to improve the flywheel design in a short time [13].

Flywheel design target is to withstand at $12000 \mathrm{rpm}$ to simulate the worst condition in vehicle. Experimental data presents that maximum stress area located near the clutch cover fixation holes due to severe section transitions. Also it is known that flywheel is safety component for powertrain systems and on the study stress behaviors located near the section areas were aimed to improve.

At the beginning of the study, flywheel was designed without slots in figure 1 . Slot geometry was considered to replace the maximum stress from critical area to another non-functional area. Initial design was gathering the stress into severe sections such as holes.
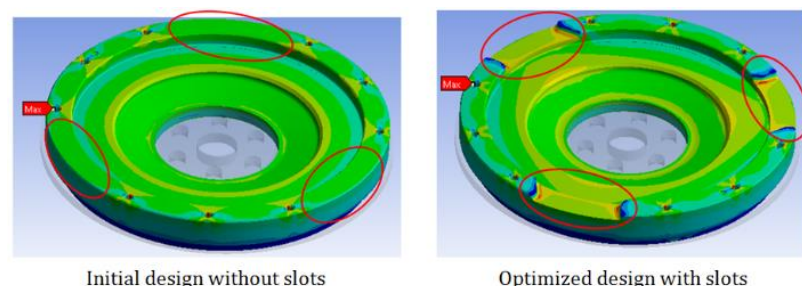

Optimized design with slots

Figure 1. Design creation with slots

In the finite element model, there are three components to be analyzed. These components are consisting of flywheel, ring gear and a fake crankshaft. Fake crankshaft was fixed from engine side. As in shown figure 2, two contact areas were defined in simulation model. First contact is located between crankshaft and flywheel. Contact type was chosen as frictional. Second contact is located between ring gear and flywheel due to shrink fitting. This contact type was chosen as frictional.

In terms of cost and machining, laminar cast iron is practical solution for flywheels. Therefore cast iron material was chosen as GJL300 laminar cast iron. Ring gear material was chosen C40 steel material. If we compare the tensile strength of ring gear and flywheel material, ring gear material have higher tensile strength than flywheel material. Maximum von-mises stress was investigated on flywheel with the guide of this information. The both material properties has given in table 1 .

Table 1. Material properties

\begin{tabular}{c|c|c|c}
\hline $\begin{array}{c}\text { Material } \\
\text { Definition }\end{array}$ & $\begin{array}{c}\text { Young } \\
\text { Modulus } \\
(\mathrm{MPa})\end{array}$ & $\begin{array}{c}\text { Poision's } \\
\text { Ratio } \\
(-)\end{array}$ & $\begin{array}{c}\text { Tensile } \\
\text { Strength } \\
(\mathrm{MPa})\end{array}$ \\
\hline $\begin{array}{c}\text { Cast Iron } \\
\text { GJL300 }\end{array}$ & 110000 & 0.26 & 300 \\
\hline Steel C40 & 210000 & 0.3 & 550 \\
\hline
\end{tabular}

Centrifugal forces mostly effect the areas which are located at severe section region and outer diameters. Therefore fixation holes should be well meshed to calculate stress level which closed to real conditions. At the mesh model, outer shapes were meshed with tetrahedron elements as shown in figure 3. Less critical areas were meshed with quad elements to decrease the element numbers of model. Thus, calculation time was minimized for each design variation.

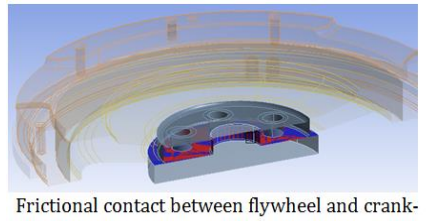

shaft

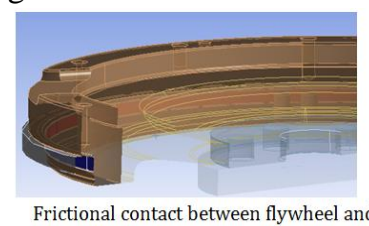

ring gear
Figure 2. Contact types 


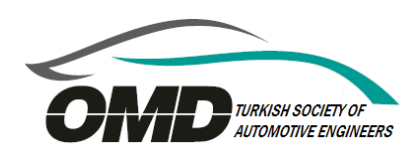

\subsection{Data fitting}

Flywheel burst simulation which gives stress value at maximum engine speed is necessary to verify flywheel design. A mathematical model analysis run is executed about five hours for flywheel burst simulation. Therefore in this study, response surface methodology is used for obtaining objective function of flywheel stress behavior. In order to obtain objective function, firstly geometrical model of flywheel was created. General shape of flywheel was designed according to limitations of clutch house space.

Another parameters of flywheel such as outer diameter or flywheel thickness must not be changed due to inertia, mass and maximum volume requirements. With slot geometry, subtraction flywheel design was finalized. Slot geometry subtraction was built for stress replacement as cyclic symmetric at $120^{\circ}$. Two shape parameters were determined for slot geometry that effects to stress replacement directly.

Then a mathematical model was created that best fits to the data which collected from experimental flywheel burst test results. According to full factorial design with four level and two parameters as shown in figure $4,24=16$ finite element analyses were executed for define a surface that approximates the behavior of the objective function. According to design of experiment results, objective function was constructed as second degree polynomial. Objective function is shown in equation 1 ;

$\mathrm{f}=224.687+4.135 \mathrm{xX}+(4754.647 / \mathrm{Y})+\left(-97781.663 /\left(\mathrm{Y}^{\wedge} 2\right)\right)(1)$

\subsection{Burst test}

Burst test is performed to evaluate centrifugal endurance of flywheel up to 2 times of the maximum engine rpm. This test is the key validation test for automobile components subjected to high revolution under operating condition. Main principles of the test initiate with the fixation of the test parts to burst test machine. Then, test machine is readyto start operating condition about to rotate at least 2 times maximum engine rpm. In general, it is expected from flywheel that it has to withstand at least 2 times of maximum engine speed.

Af-

ter this test, parts are visually analyzed in order to control whether any cracks and breakages occurs. The parts are expected to complete burst tests without any cracks and breakages. Even small cracks are not accepted due to the fact that it leads to possible cracks if it continuous to high rotation. As flywheels are considered safety parts in powertrain system, it needs to be well analyzed detailed to avoid of any failure.

\section{Analysis and Tests}

\subsection{FEA analysis}

At the beginning of the study, mesh size choice was studied on initial flywheel design to run all analysis efficiently. Different mesh sizes were compared at the figure 5. This comparison shows us that mesh size doesn't effect the maximum stress results significantly. It can be seen clearly at the figure 6 below. In this study, all calculations were done according to $4 \mathrm{~mm}$ mesh size.

Figure 5. Comparison mesh size between $4 \mathrm{~mm}$ and $2.5 \mathrm{~mm}$

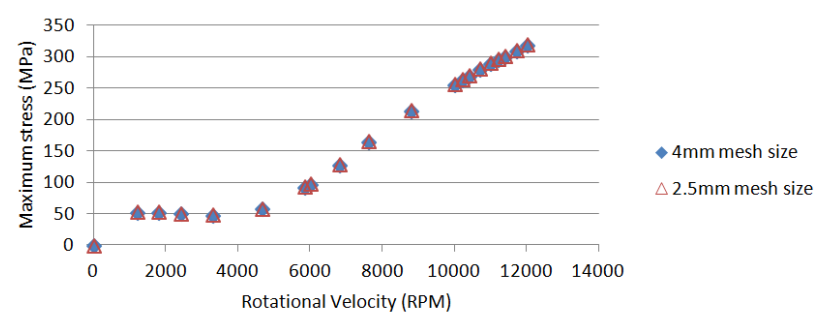

After model creation, sixteen FEA study were implemented to find von-mises stress level against to change of slot width and depth. As shown on figure 6, most critical areas are similar locations at outer diameter and on fixation holes as mentioned in previous section 2 . The both parameters especially were selected applicable values according to design constraints.

Calculated results at $12000 \mathrm{rpm}$ with simulations create an indicator database to find the relationship between two design parameters and maximum von-mises stress. As showed in table 2, sixteen FEA results are listed according to two design parameters.

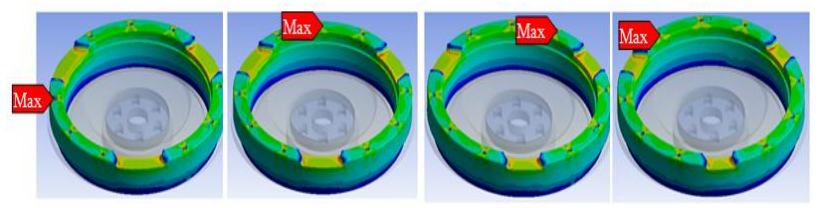

Figure 6. Some pictures from different FEA results

If listed results are filtered, it is seen that slot designs helped to decrease the stress level of initial flywheel design. Maximum stressed area was revealed thanks to another severe section changes on flywheel. The best improvement was seen with design number 1 includes depth $5 \mathrm{~mm}$ and width $68 \mathrm{~mm}$ parameters.

In initial design, maximum stressed area was $318.42 \mathrm{MPa}$ on fixation hole at outer diameter. Thus, there was a stress decrease of $7.6 \%$ at maximum stressed area from $318.42 \mathrm{MPa}$ to 294.07 MPa. But some design parameters could not improve the stress level. Design number 15 includes $8 \mathrm{~mm}$ slot depth and $48 \mathrm{~mm}$ slot width. These parameters combinations cannot give an improvement due to that it has similar results about $318 \mathrm{MPa}$ as in initial design. 
Table 2: FEA results and objective function results at $12000 \mathrm{rpm}$

\begin{tabular}{c|c|c|c|c|c}
\hline & $\begin{array}{c}\text { Slot } \\
\text { Depth } \\
\text { X } \\
(\mathrm{mm})\end{array}$ & $\begin{array}{c}\text { Slot } \\
\text { Width } \\
\text { Y } \\
(\mathrm{mm})\end{array}$ & $\begin{array}{c}\text { Objec- } \\
\text { tive } \\
\text { Func- } \\
\text { tion } \\
\text { Result } \\
\text { (MPa) }\end{array}$ & $\begin{array}{c}\text { FEA } \\
\text { Result } \\
(\mathrm{MPa})\end{array}$ & $\begin{array}{c}\text { Deviation be- } \\
\text { tween FEA Re- } \\
\text { sult and Objec- } \\
\text { tive Function } \\
(\%)\end{array}$ \\
\hline Initial Design & $\begin{array}{c}\text { Not } \\
\text { avail- } \\
\text { able }\end{array}$ & $\begin{array}{c}\text { Not } \\
\text { avail- } \\
\text { able }\end{array}$ & $\begin{array}{c}\text { Not } \\
\text { availa- } \\
\text { ble }\end{array}$ & 318,42 & $\begin{array}{c}\text { Not } \\
\text { available }\end{array}$ \\
\hline Design 1 & 5 & 68 & 294,13 & 294,07 & $-0,02 \%$ \\
\hline Design 2 & 5 & 58 & 298,27 & 298,12 & $-0,05 \%$ \\
\hline Design 3 & 5 & 48 & 301,97 & 301,3 & $-0,22 \%$ \\
\hline Design 4 & 5 & 38 & 302,76 & 305,43 & $0,88 \%$ \\
\hline Design 5 & 6 & 68 & 298,27 & 295,42 & $-0,96 \%$ \\
\hline Design 6 & 6 & 58 & 302,40 & 299,72 & $-0,89 \%$ \\
\hline Design 7 & 6 & 48 & 306,11 & 301,22 & $-1,60 \%$ \\
\hline Design 8 & 6 & 38 & 306,90 & 305,33 & $-0,51 \%$ \\
\hline Design 9 & 7 & 68 & 302,40 & 301,78 & $-0,21 \%$ \\
\hline Design 10 & 7 & 58 & 306,54 & 308,21 & $0,54 \%$ \\
\hline Design 11 & 7 & 48 & 310,24 & 310,65 & $0,13 \%$ \\
\hline Design 12 & 7 & 38 & 311,03 & 312,83 & $0,58 \%$ \\
\hline Design 13 & 8 & 68 & 306,54 & 309,47 & $0,96 \%$ \\
\hline Design 14 & 8 & 58 & 310,67 & 314,79 & $1,32 \%$ \\
\hline Design 15 & 8 & 48 & 314,38 & 318,67 & $1,36 \%$ \\
\hline Design 16 & 8 & 38 & 315,17 & 322,49 & $2,32 \%$ \\
\hline
\end{tabular}

Additionally, objective function results were listed on table 1. Used parameters in FEA calculations re-calculated with objective function equations. The both calculations of objective function and FEA results were compared to show the deviation ratio.

Comparing to simulated parameters in finite element models, objective function have maximum $2.32 \%$ deviation in terms of stress level. If it is considered with calculation time of 16 finite element models, they take approximately 80 hours totally. Whereas objective function can easily calculate the results in only a few seconds by any parameters which in range of maximum and minimum design constraints.

According to objective function results, response surface is shown on figure 7 . When the response surface is analyzed, it is observed that the results do not change with linear trend. In terms of better stress level, slot width should be wider and slot depth should be lesser depth in this type of flywheel which has similar design. With response surface method, best parameter combination can be chosen on graph. In this way, a fast prediction can be performed in the beginning of the project.
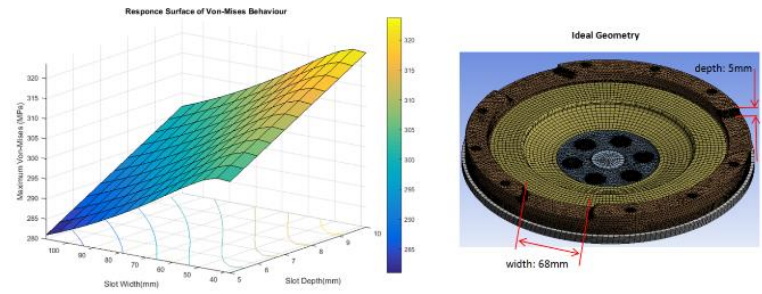

Figure 7. Response surface graph of objective function

\subsection{Burst test result}

In this section experimental tests are done between the flywheels with and without slots in order to prove correlation between the FEA analyses illustrated at previous section. As resulted significantly by FEA, slots effects on improvement of stress behavior are investigated by making comparative test between both designs.

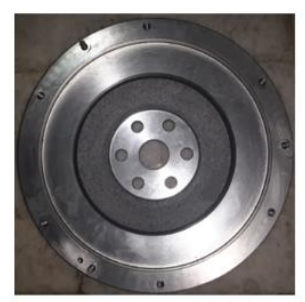

Without slots (Initial Design)

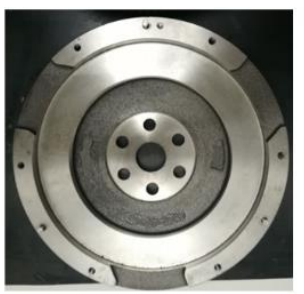

With slots

Depth: $5 \mathrm{~mm} \&$ Width: $68 \mathrm{~mm}$ (Ideal Geometry)
Figure 8. Comparative experimental bench test

All test parts with and without slots were precisely chosen at the same casting batch to avoid of material and process differences. 3 parts were tested for each design that all of them are from same batch and casting. Tensile strengths were found averagely about $312 \mathrm{Mpa}$ for 9 parts with and without slot. These are the summary table for the tested parts shown at table 3 .

Table 3: Comparative experimental burst tests

\begin{tabular}{c|c|c}
\hline Part No & $\begin{array}{c}\text { Burst point for } \\
\text { Flywheel without } \\
\text { slots (RPM) }\end{array}$ & $\begin{array}{c}\text { Burst point for } \\
\text { Flywheel with } \\
\text { slots (RPM) }\end{array}$ \\
\hline Part 1 & 11892 & 13404 \\
\hline Part 2 & 12050 & 12612 \\
\hline Part 3 & 11632 & 12958 \\
\hline $\begin{array}{c}\text { Average burst } \\
\text { point }\end{array}$ & 11858 & 12991 \\
\hline
\end{tabular}

It is clearly seen on tested parts that slots which was machined on the flywheels have big importance upon the improvement of the stress behavior of the mechanical endurance. By means of the slots which have located on the flywheels, nearly 1100 RPM increment for the burst point was obtained. This increment enables us to exceed 12000 RPM 


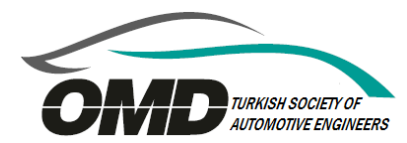

average validation limit for the car which has 6000 maximum engine speed.

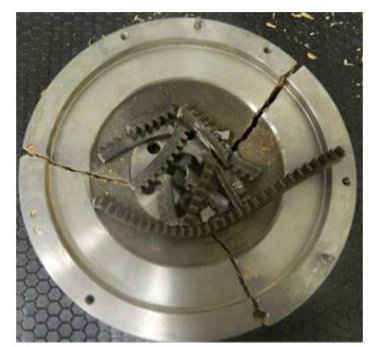

Without slots

(Initial Design)

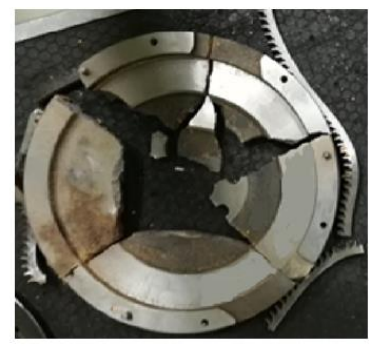

With slots

(Ideal Geometry)
Figure 9. Broken flywheels after burst test

If we observe correlation between FEA and bench test in term of burst point, both results are closed to each other. As seen on table 4 , correlation ratio of initial design calculation with bench test is $0.6 \%$. Improved design with slot geometries has $2.5 \%$ correlation ratio with bench test. This calculation approach provides to make design closed to real conditions.

Table 4: Correlation between FEA results and bench test results

\begin{tabular}{|c|c|c|c|c|}
\hline & $\begin{array}{c}\text { Tensile } \\
\text { Strength } \\
\text { Measurement } \\
\text { (Average of 9 } \\
\text { parts) }\end{array}$ & $\begin{array}{c}\text { Bench } \\
\text { Test } \\
\text { Results } \\
\text { (Aver- } \\
\text { age of 3 } \\
\text { parts) }\end{array}$ & $\begin{array}{c}\text { Fea } \\
\text { Re- } \\
\text { sults }\end{array}$ & $\begin{array}{c}\text { Correla- } \\
\text { tion Be- } \\
\text { tween } \\
\text { FEA and } \\
\text { Bench } \\
\text { Test }\end{array}$ \\
\cline { 1 - 4 } $\begin{array}{c}\text { Initial design } \\
\text { without slot }\end{array}$ & 311.93 & 11858 & 11787 & $0.6 \%$ \\
\cline { 1 - 1 } $\begin{array}{c}\text { New design } \\
\text { with slot } \\
5 \mathrm{mmx68mm}\end{array}$ & $\mathrm{MPa}$ & 12991 & 12667 & $2.5 \%$ \\
\cline { 1 - 4 } & & RPM & RPM & \\
\hline
\end{tabular}

\section{Results and discussions}

Today, new engine technology requirements such as high speed, lower volume in clutch house and higher performance become important in automotive industry. These constraints make flywheel design difficult in order to create robust flywheel design. Therefore improvement of stress level on flywheel is important especially during design process.

After design change with slots creation, stress improvement was observed. The study shows that slot design helps to replace the maximum stress from most critical area to nonfunctional area. Sixteen different design studies were realized with FEA calculations to find the experimental values. Thus, stress level on flywheel was decreased $7.7 \%$ on most critical areas. With design of experiment study, flywheel development process has been completed faster and cheaper. And also a correlation was seen between objective function and FEA results. Maximum deviation ratio is $2.32 \%$ between objective function and FEA results. In addition to FEA, experimental comparison done with real parts on burst test machine. Results were seems that all of them are proportional with analysis results. With new design of flywheel, FEA correlation was found $2.5 \%$ with experimental bench test results. This study shows us the way of stress improvement of automobile flywheels both numerically and experimentally. Burst numerical and experimental comparative data also can be applicable for the other rotational parts subjected to friction in powertrain systems.

As a summary, this method provided benefits in terms of shortening calculation time and decreasing prototyping cost. In next studies, this method will be considered for thermomechanical calculation which simulates heat-flux on friction surface of flywheel.

\section{References}

[1] Karpat, F., Doğan, O., Yuce, C., Genc, M. O., 'Design Verification of Tractor Clutch Cover Under Centrifugal Effect', Int. J. of Automotive Science and Technology, 2017, Vol.1, No:1, 29-33.

[2] Karpat, F., Dogan, O., Yuce, C., Kaya, N. and Cengiz, G., 'The investigation of stress distribution on the tractor clutch finger mechanism by using finite element method', Proceedings of the ASME 2014 International Mechanical Engineering Congress \& Exposition, Montreal, Canada, 2014.

[3] Dogan, O., Karpat, F., Kaya, N., Yuce, C., Genc, M.O., and Yavuz, N., 'Optimum design of tractor clutch PTO finger by using topology and shape optimization' Proceedings of the ASME 2015 International Mechanical Engineering Congress \& Exposition Houston, Texas, USA, 2015.

[4] Dogan, O., Karpat, F., Yuce, C., Kaya, N., Yavuz, N. and Sen, H. (2016). A novel design procedure for tractor clutch fingers by using optimization and response surface methods. Journal of Mechanical Science and Technology, 30, (6), 2615-2625.

[5] Charles, X., 'Design and Stress Analysis of Composite Material Flywheel in Automotive', Middle-East Journal of Scie tific Research 12 (12): 1620-1624, 2012

[6] Abdullah, O. I., Schlattmann, J.,Al Shabibi, A. M., 'Stresses and Deformations Analysis of a Dry Friction Clutch System', Tribology in Industry Vol. 35, No. 2, 155162,2013

[7] Bharwaj, M., Bhardwaj, S., 'Design and Analysis of Light Weight Motor Vehicle Flywheel' International Journal of Innovation Sciences and Research,Vol.4, No, 8, pp.61365, August- 2015

[8] Abdullah, O. I., Schlattmann, J., 'Contact Analysis of a Dry Friction Clutch System' Hindawi Publishing Corporation, ISRN Mechanical Engineering, Article ID 495918, Volume 2013

[9] Abdullah, O. I., Schlattmann, J., ' Finite Element Analysis of Temperature Field in Automotive Dry Friction Clutch' Tribology in Industry, Vol.34, No.4-2012, pp. 206- 
[10] Hongliang, L., Jiangwei, C., Jialu, L., Pengfei, C., Zhanzhong, W., 'Energy recovery data characteristics extraction of flywheel energy storage control system for vehicular applications', Advances in Mechanical Engineering, Vol.9(4)-2017, pp.1-11

[11] Ozansoy, O., Tevruz, T.,Mugan, A., 'Multiobjective Pareto Optimal Design of a Clutch System', International Journal of Engineering Technologies. Vol.1, No.1-2015, pp. $25-43$

[12] Vasca, F., Lanelli, L., Senatore, A., Scafati, M., 'Modeling Torque Transmissibility for Automotive Dry Clutch Engagement', American Control Conference, June 11-13, 2008, pp. 306-311.

[13] Tipirineni, M. K., Rao, P., 'Optimal Design of a Clutch Plate using Ansys', International Journal Of Computational Engineering Research, Vol. 03 Issue. 12, 2013 